\section{Charles Darwin as a theoretical biologist in the mechanistic tradition}

\author{
David Penny \\ Allan Wilson Center for Molecular \\ Ecology and Evolution, Massey \\ University, Palmerston North, \\ New Zealand
}

\section{Abstract}

Charles Darwin has had more impact on biological sciences, and society generally, than any other $19^{\text {th }}$ century biologist. Yet his modus operandi as a scientist is poorly known by evolutionists, and often seriously misinterpreted. Two important aspects of his reasoning discussed here are his hypothetico-deductive approach and his search for mechanisms to explain past events. A wide range of statements from his autobiography and letters show that he worked explicitly in the hypotheticodeductive model. The extracts include strong statements that theories were essential even to know what data to collect; to hold theories only as hypotheses; the necessity to search for data that contradict a cherished theory. He also built on the very mechanistic geological tradition of James Hutton and Charles Lyell, and thus brought into historical biology the search for mechanisms that could be studied in the present to explain events in the past. Taken together, the statements show an excellent scientist working effectively on conceptual issues, whilst searching for mechanisms that could be studied in the present and that would have operated in the past. In retrospect, our understanding has been hampered by forcing overly-simplistic binary choices, such as uniformitarianism and catastrophism. It is important, especially in teaching and interactions with the public, that Darwin's mode of working is better known, and we need to be more proactive in getting across the message that evolution is good testable science.

As an evolutionary biologist, I think the work of Charles Darwin holds a strong message for all those interested in how good science should be done and in demonstrating the testability of evolutionary theory. Innovative science and testability of hypotheses are both scientifically important questions but are also helpful for both education and in involving the public in discussions about evolution. In many areas of science, major developments have been followed by many subsidiary developments and improvements in understanding mechanisms, but in evolution there was little major development in theory from 1859 until the new synthesis ${ }^{1}$ in the 1930 s onwards. ${ }^{2}$ I illustrate this by two extracts, the first from 1921 and the second from 1929.

"For the moment, at all events, the Darwinian period has passed. ... All again is in the melting pot. By now, in fact, a new generation has grown up that knows not Darwin".

"Whilst the fact of evolution is accepted by every biologist the mode in which it has occurred and the mechanism by which it has been brought about are still disputable. ... and Darwin, rest on a most insecure basis; the validity of the assumptions on which they rest has seldom been examined and they do not interest most of the younger zoologists"4 (emphases added).

All this has now changed and Darwin's reputation about mechanisms of evolution is reestablished among evolutionists. Many areas of the study of evolution are now quantitative and go well beyond what was possible in the mid-nineteenth century. In the 1930s, population genetics, from the work of the triumvirate of Fisher, Haldane and Wright, became the first area to become quantitative ${ }^{1}$ but other areas have followed. Our own area of interest, the study of evolutionary trees, ${ }^{5}$ is a more recent example. Consequently it is natural to ask, was there something about Charles Darwin's thinking/reasoning/knowledge that led him in several areas to be so innovative in his thinking about the mechanisms of evolutionary biology? Can we use such information to be more proactive in teaching about evolution?

Perhaps the complexity of Darwin's overall theory ${ }^{6}$ was one reason why, qualitatively, his thinking was not surpassed until the 1930s. We have found it useful for analyzing the many components of Darwin's theory to simplify them to three major aspects:?

the microevolutionary processes that can be studied in the present (Figure 1A, summarized as 'natural selection');

macroevolution in referring to Darwin's theory of descent with modification (Figure 1B);

the Darwinian hypothesis (Figure 1C) that the processes of microevolution that can be studied in the present are sufficient to fully account for macroevolution in Part B. This latter part still needs to be fully addressed by evolutionists.

The approach of explaining past events in terms of mechanisms that can be studied in the present is actualism ${ }^{8}$ and it makes no assumptions about constant rates, in the way that uniformitarianism is often (unfortunately) interpreted (see below). There are other ways to analyze Darwin's theory; Mayr ${ }^{9}$ considered it as five theories. What is important here is that the overall theory, together with its consequences, is relatively complex, even though
Correspondence: David Penny, Allan Wilson Center for Molecular Ecology and Evolution, Massey University, Palmerston North, New Zealand. E-mail: d.penny@massey.ac.nz

Key words: mechanisms of evolution, conjectures and falsification, geology, philosophy of science, theoretical biology, role of hypotheses.

Received for publication: 11 July 2009

Revision received: 26 August 2009.

Accepted for publication: 26 August 2009.

This work is licensed under a Creative Commons Attribution 3.0 License (by-nc 3.0).

(C) Copyright D. Penny 2009

Licensee PAGEPress, Italy

Trends in Evolutionary Biology 2009; 1:e1

doi:10.4081/eb.2009.e1

the individual ideas are both relatively simple and testable. ${ }^{6}$

Right back to at least Ghiselin, ${ }^{10}$ historians of biology appear to have had a better understanding of Darwin's approach to science than do many ordinary biologists. Nevertheless, their work appears (unfortunately) to have had insufficient impact on biologists, and historians do not necessarily emphasize all the issues important to researchers (such as Darwin's emphasis on mechanisms, discussed later). We need to present the conclusions about Darwinian reasoning in a way relevant to evolutionists, and it will help their interpreting evolution to others. The two main themes considered here are Darwin's explicit use of hypotheses for testing (conjectures and falsification, or hypothetico-deductive reasoning) and his geological background which led him to search for present-day mechanisms that could explain events in the past. This latter approach comes quite directly from the similar mechanistic reasoning of Charles Lyell in the 1830 s, and at the time it was recognized that Lyell had further developed the ideas of James Hutton of the 1790s. Studying the modus operandi of innovative and successful scientists should help all scientists. In addition, I emphasize that it is misleading to try to force diverse ideas into overly-simplistic binary choices, such as uniformitarianism versus catastrophism. Taken together, it is hoped that the analysis presented here will help evolutionists in their own work and in presenting evolution to others. Perhaps it is time that evolutionists took more initiative in asserting that evolution is central to all of biology and to our understanding of ourselves and our societies. Evolutionists could be more proactive, rather than waiting to respond to challenges from others. The increase in all types of biological data, including genomics, gives a new beginning to many evolutionary studies. 


\section{Darwin's hypothetico-deductive reasoning}

There has often been an assumption among biologists that Darwin simply collected data, and almost 'stumbled' across his theory. Nothing could be further from reality, but the conclusion is often based on a well known quote in his autobiography ${ }^{11}$ that is usually taken out of context. The whole statement is given below, but it is the part in bold that is usually quoted. It is perhaps best to read the part in bold first, and then to go back and read the whole extract.

"It was evident that facts such as these, as well as many others, could be explained on the supposition that species gradually became modified; and the subject haunted me. But it was equally evident to me that neither the action of the surrounding conditions, nor the will of the organisms (especially in the case of plants), could account ... I had always been much struck by such adaptations, and until these could be explained it seemed to me almost useless to endeavour to prove by indirect evidence that species had been modified.

"After my return to England it appeared to me that ... by collecting all facts which bore in any way on the variation of animals and plants under domestication and [in] nature, some light might perhaps be thrown on the whole subject. My first note-book was opened in July 1837. I worked on true Baconian principles, and without any theory collected facts on a wholesale scale, more especially with respect to domesticated productions, by printed enquiries, by conversation with skilful breeders and gardeners, and by extensive reading" ${ }^{12}$ (pp.118-9).

Thus the quotation as a whole gives a very different picture than just the portion in bold. It is clear that the hypothesis 'that species gradually became modified' (evolution) was "haunting" Darwin. The extract shows six main points. Darwin had;

- concluded that continued and gradual evolution of species was possible (and likely);

- rejected Plato's concept of an 'unchangeable essence' for species;

rejected the direct 'action of the environment' as a potential mechanism;

- rejected the 'will of the organism' as a potential mechanism;

started searching for other mechanisms to explain adaptations; and

- focused on variation within species and on artificial selection for mechanisms.

Thus he had already identified the key question, rejected two potential mechanisms, and was focusing on both natural variation and on plant and animal breeding for ideas about mechanisms. It was important that he had already rejected the nemesis of many (but certainly not all) earlier biologists - namely, that

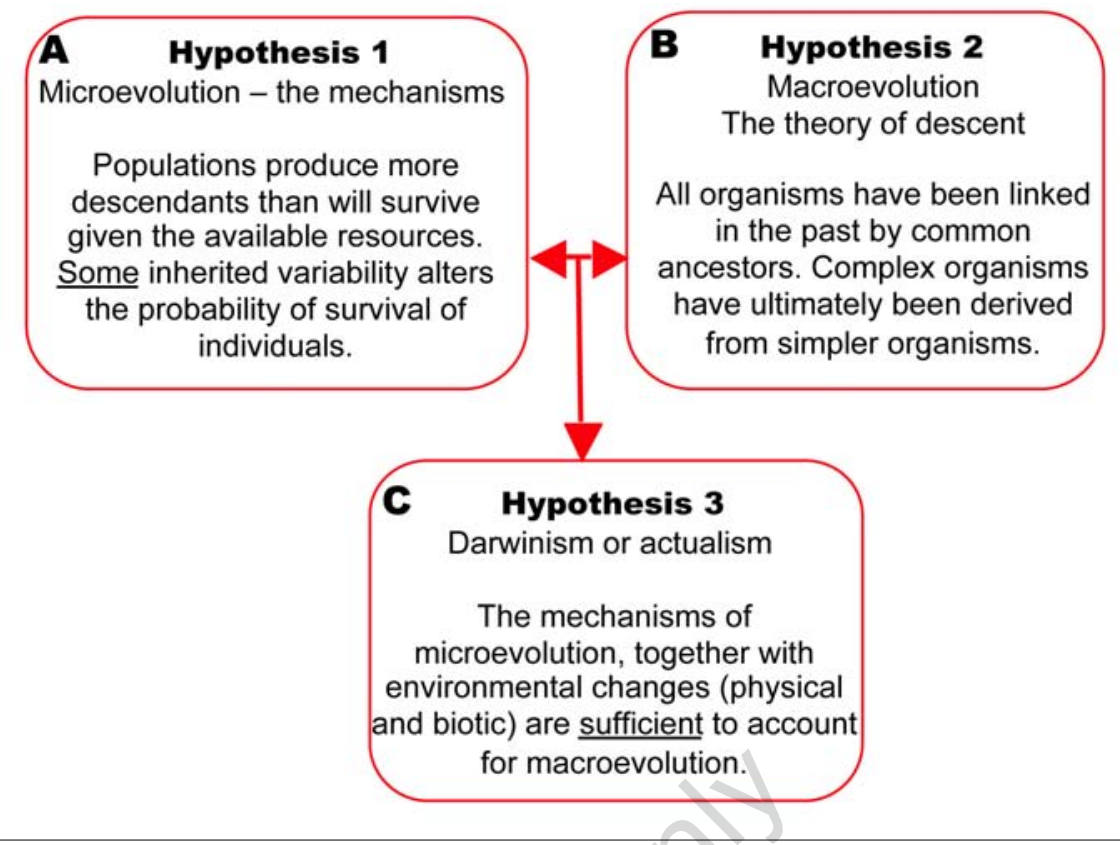

Figure 1. Three main components of Darwin's theory. They are mutually supporting in that, for example, the theory of descent is supported by the existence of a mechanism that could lead to species modification and divergence; but the theory of descent also leads to a search for mechanisms that would result in descent with modification. Hypothesis 3 is the one still being debated by a few evolutionists. ${ }^{7}$

each species had an unchangeable 'form' or 'essence' - a philosophical concept from Plato and Aristotle that was being applied to 'species'. If 'species' really did have an 'essence', then any continued change (virtually by definition), was impossible. Thus the full quotation is very informative about Darwin's thinking at the time of starting his notebooks, and certainly shows a far more sophisticated reasoning than just 'collecting facts'.

In addition, Darwin was simultaneously reading widely in science and the philosophy of knowledge. ${ }^{13,14}$ Indeed, on the very next page of his autobiography, after reading Quetelet and Malthus, we find the opening quotation, "Here, then, I had at last got a theory by which to work"12 $^{\prime \prime}$ (p.120). That statement is worth reading again: "I had at last got a theory by which to work". Darwin was certainly not suggesting in the earlier extract that 'collecting facts' was sufficient for a scientist; rather he was bemoaning that 'not having a theory by which to work' he was reduced to collecting facts (okay, as well as reading widely in his selected areas). Even in his reading he had narrowed down the area (natural variation, and artificial selection in domesticated plants and animals) where he was looking for information.

Thus we have a prima facie case that he had a well developed conceptual understanding of science; it was not a coincidence that Charles Darwin was looking for predictions from theories. During the early stages of the development of his theory (after the voyage of the
Beagle) Darwin read widely in many areas of science; partly in order to understand what was required of a good scientific theory. His reading included works by John Herschel, Dugald Stewart, William Whewell, ${ }^{15}$ and August Comte. Each of these authors emphasized the importance of prediction in science and, judging from letters to Charles Lyell, ${ }^{13}$ Darwin was well aware of the importance of a good scientific theory leading to predictions. Even at an early stage (1838) we find the quote, "there are some fine sentences about the very essence of science being prediction"16 (p.104; see also below).

The hypothetico-deductive method is often associated now by scientists with Karl Popper from the mid $20^{\text {th }}$ century. ${ }^{17}$ However, as mentioned above, the ingredients of good science were actively discussed 100 years earlier, including Whewell's advocacy of using different lines of evidence to support a theory, his 'consilience of induction'. It is in this 'conceptual' or 'hypothetico-deductive' framework that Darwin can be considered a theoretical biologist (though not as a mathematical biologist, which is another important area of theoretical biology). The conclusion that Darwin worked in a hypothetico-deductive mode is similar to that of Ayala, ${ }^{11}$ though our interpretation of the main extract differs partially.

\section{Conjectures and falsification in Darwin's writings}

To show the extent of Darwin's commitment to predictions and testing I will first give a series of quotations from his autobiography. ${ }^{12}$ 
For example, when criticizing the work of Herbert Spencer (founder of 'social Darwinism') Darwin made the comment, "His [Spencer's] fundamental generalisations ... do not seem to me to be of any strictly scientific use. ... They do not aid one in predicting what will happen in any particular case"12 (p.109). Again, it was important to take note of evidence that potentially conflicted. "I had, also, during many years, followed a golden rule, namely, that whenever a published fact, a new observation or thought came across me, which was opposed to my general results, to make a memorandum of it without fail and at once; for I had found by experience that such facts and thoughts were far more apt to escape from the memory than favourable ones. Owing to this habit, very few objections were raised against my views which I had not at least noticed and attempted to answer"12 (p.123).

Even discarded hypotheses may be of use if they lead to better ideas. "Towards the end of the work I give my well-abused hypothesis of Pangenesis. An unverified hypothesis is of little or no value. But if any one should hereafter be led to make observations by which some such hypothesis could be established, I shall have done good service, as an astonishing number of isolated facts can thus be connected together and rendered intelligible ${ }^{, 12}$ (p.130).

Other quotations on a similar theme follow: "... for in accordance with the principles of evolution it was impossible to account for climbing plants having been developed in so many widely different groups, unless all kinds of plants possess some slight power of movement of an analogous kind. This I proved to be the case, and..."12 (p.135). "I have steadily endeavoured to keep my mind free, so as to give up any hypothesis, however much beloved (and I cannot resist forming one on every subject), as soon as facts are shown to be opposed to it ${ }^{\prime \prime 2}$ (p.141).

"Insectivorous Plants was published July 1875, - that is sixteen years after my first observations. The delay in this case, as with all my other books, has been a great advantage to me; for a man after a long interval can criticize his own work, almost as well as if it were that of another person"12 (pp.132-3). In 1838-39 Darwin noticed dimorphism (two forms) of flowers in primroses, and "first thought that it was merely a case of unmeaning variability... the two forms were much too regular and constant to be thus viewed. I therefore became almost convinced that the common cowslip and primrose were on the high road to become dioecious; - that the short pistil on the one form, and the short stamens in the other were tending towards abortion. The plants were therefore subjected under this point of view to trial ... the abortion theory was knocked on the head. ... ${ }^{12}$ (p.128). On this subject Darwin had had three hypotheses in succession: unmeaning variability (presumably random variation unrelated to the function of the flower);

an 'intermediate step to becoming dioecious' (having separate male and female plants); and

an 'outcrossing mechanism'.

Again there is a cycle of observation, hypothesis, and testing of ideas.

\section{Is this just being 'wise after the event'?}

These quotations are from Darwin's autobiography ${ }^{12}$ which was mostly written in 1876 , with updates until 1882. Thus his autobiography was written nearly 20 years after the Origin was published, and so we could consider an alternative hypothesis that the quotations just showed Darwin being 'wise after the event' in attributing so much importance to theories and testing them. We have already given a quote from $1838^{16}$ (p.104) that contradicts this possibility and in general it can be tested (and rejected) by examining writings from earlier periods; here we will focus on extracts from his letters from 1856-1857. ${ }^{18} \mathrm{By}$ the mid-1850s, Darwin was already working on his 'big book' on Natural Selection, but it was before he received the letter from $A$. $R$. Wallace indicating that Wallace had independently developed very similar ideas. However, at this earlier stage we still see Darwin's advocacy of the role of theory and testing.

The following quotes are from letters from 1856-1857. In response to a letter from C.J.F. Banbury we read, "My determination to put difficulties, as far as I can see them, on both sides is a great aid to candour; because I console myself, when finding some great difficulty, in endeavouring to put it as forcibly as I can"18 (pp.80-1). Again, in a letter to J. D. Hooker the following statement includes both falsifiability and testing aspects of theories: "You say most truly about multiple creations \& my notions; if any one case could be proved I should be smashed: but as I am writing my Book, I try to take as much pains as possible to give the strongest cases opposed to me ..." ${ }^{\prime 18}$ (p.178). And $\operatorname{again}^{18}$ (p.190) he is encouraging Hooker to cross plants and will help guide him to some of the most difficult cases. Two weeks later he informs Hooker that, "Tyndall's pamphlet is capital \& has made me finally give up a cherished opinion, ... Ion cleavage under pressure in rocks]" (p.201), and later "How many astronomers have laboured their whole lives on observations \& have not drawn a single conclusion; I think it is Herschel who has remarked how much better it would be, if they paused in their devoted work \& seen what could be deduced from their work"18 (p.360). Later again, "It is my intention to give fully all the facts in favour of the eternal immutability of species \& I have taken as much pains to collect them, as I possibly could do"18 (p.236 in a letter to J. D. Dana).

The following two quotes are from a letter to T.H. Huxley, "... it seems to imply that there are varieties of the Domestic Bee; about which I feel an especial interest; for Bees offer in one respect by far my greatest theoretical difficul${ }_{t y}{ }^{\prime \prime 8}$ (p.301) and “... but I always give all the facts which I can collect hostile to my notions"18 (p.307). In early correspondence with A. R. Wallace (before Wallace revealed his ideas on natural selection) Darwin commented that facts do not determine interpretation, and that conviction was not the slightest guarantee of truth, "...for it is lamentable how each man draws his own different conclusions from the very same fact. ... Whether true or false others must judge; for the firmest conviction of the truth of a doctrine by its author, seems, alas, not to be the slightest guarantee of truth. ${ }^{\prime 18}$ (p.387); and "I am extremely glad that you are attending to distribution in accordance with theoretical ideas. I am a firm believer, that without speculation there is no good \& original observa tion." ${ }^{\prime 18}$ (p.514).

Some of the most revealing statements are in letters to Asa Gray of Harvard. "To be brief I assume that species arise like our domestic varieties with much extinction; \& then test this hypothesis by comparison with as many general \& pretty well established propositions as I can find out, - in geographic distribution, geological history - affinities, \&c\&c\&c. And it seems to me that supposing that such hypothesis were to explain general propositions, we ought, in accordance with common way of following all sciences, to admit it, till some better hypothesis be found out." (p.432) and “...\& think I go as far as almost anyone in seeing the grave difficulties against my doctrine"Is (p.445); "What you hint at generally is very very true, that my work will be grievously hypothetical \& large parts by no means worth of being called inductive;"'s (p.492). This last comment is especially interesting, Darwin certainly did not see himself as just collecting 'facts' and then coming to inductive conclusions.

Again, a little later in correspondence from 1861, ${ }^{19}$ "About thirty years ago there was much talk that geologists ought only to observe and not theorise; and I well remember some one saying that at this rate a man might as well go into a gravel-pit and count the pebbles and describe the colours. How odd it is that anyone should not see that all observation must be for or against some view if it is to be of any service!" (p.269) and a similar statement, "If you don't have a theory you might just as well count the stones on Brighton beach". Anyone who has looked at several miles of stones that make up Brighton "beach" will find this striking. The Myth of Sisyphus, condemned to continually 
roll a stone to the top of a hill and let it roll down again and again and again, pales in comparison to counting the stones of Brighton Beach. At least Sisyphus had a defined, if ever repeating task. The number of stones on Brighton beach changes minute by minute as the tide changes; it is both impossible and pointless, as well as a never ending task. To be practical, having "at last got a theory by which to work", is very important for researchers.

Those extracts are mainly from his letters of 1856-57, and clearly complement those from his autobiography two decades later. There is nothing special about those times, others would serve equally well. The Origin itself has the powerful statement, "If it could be demonstrated that any complex organ existed which could not possibly have been formed by numerous, successive, slight modifications, my theory would absolutely break down. ${ }^{\prime 20}(\mathrm{p} .189)$. This quote ('my theory would absolutely break down') is another example of how Charles Darwin considered his theory of evolution to be falsifiable, and therefore scientific. It is worth noting here that there is nothing in the above statement that assumes equal rates of change, just 'numerous successive slight modifications' - there is certainly no 'phyletic gradualism' in that statement (see below).

Although Darwin is remembered today for his overall theory of evolution, in his day to day research he made many predictions from his theory - then sought to test them. Some of the best known involve his experiments on plants including work on orchid flowers (particularly on the benefits to the plants from an outcrossing mechanism), pin and thrum flowers of primrose (and other dimorphic and trimorphic forms of flowers) and on the power of movement of plants. ${ }^{10,21}$ This last example of the power of movement in plants is particularly interesting, and we have already seen a record of his reasoning predicting that all "plants possess some slight power of movement of an analogous kind'. Even earlier, in his notebooks, he had asked, "Is there any very sleepy mimosa, nearly allied to the Sensitive Plant?". The prediction that all plants should have some 'slight power of movement' led to his two books on this research, "The Movements and Habits of Climbing Plants" and "The Power of Movement in Plants". These examples are just tips of the proverbial iceberg, many others on how Darwin used predictions to direct research could be given, including features of human evolution. As just one example, Darwin (in 1872, based on a very early use of questionnaires) concluded that there were some human emotions and expressions that were 'universal' among humans. It is only in the last few decades (after 100 years of non-acceptance of evolutionary ideas applying fully to humans) that such conclusions are becoming accepted. $^{22}$

Darwin's papers by subject area.

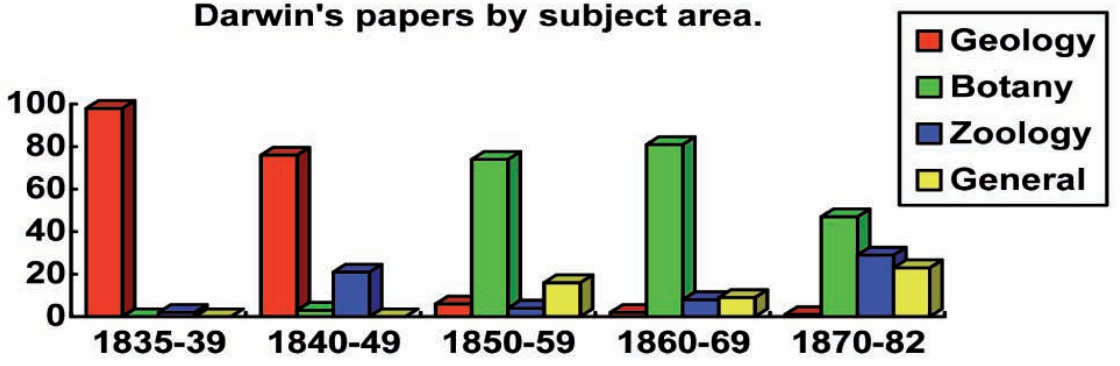

Figure 2. Darwin's papers by subject area and time. For each decade the number of pages of scientific papers ${ }^{29}$ is counted by subject area (excluding books), and then expressed as a percentage of the total pages published in each subject. Time periods are based around 1859 when the Origin was published. 'General' includes psychology and child development as well as evolutionary theory. The early publications by the young Charles Darwin were primarily in geology, his later ones almost exclusively in biology.

This section makes it clear that Darwin was consciously aware of the importance of hypotheses, and testing them, even while he was still developing his theory of evolution by natural selection. Not only did he work consciously in a hypothetico-deductive model but he also was open to, and sought, evidence that could potentially falsify his hypotheses - good science. From the viewpoint of modern scientists, it is difficult to imagine any scientist in the $19^{\text {th }}$ century being more 'Popperian'. Thus, such an approach to science has a long history - there is nothing to limit it to the $20^{\text {th }}$ century.

\section{The relationship between Darwin} and the geologists Hutton and Lyell

The next question is the source of Charles Darwin's very mechanistic approach to historical biology; his insistence on searching for current mechanisms that might explain past biology. We saw in the first extract from Darwin's writings (given earlier) that even by the time he started his notebooks he was looking toward domestication, and to plant and animal breeders, for ideas on the processes that may be involved. He had already rejected two possible mechanisms of change. In the $1830 \mathrm{~s}$ there was already a healthy debate within geol${ }_{0} \mathrm{gy}^{23}$ about explaining past geological events by mechanisms that can be studied in the present. So here we turn to geology.

It is perhaps sufficient here to say that the largest single influence on developing Darwin's search for mechanisms was Charles Lyell (1797-1875) and his "Principles of Geology" ${ }^{24}$ Although Darwin had studied some geology earlier (at both Edinburgh and Cambridge), it was only during the voyage of the Beagle that he had the opportunity of evaluating Lyell's approach. Darwin took the first volume of Lyell's Principles on the Beagle, and received the other two volumes during the voyage itself. Lyell himself followed another earlier Scottish geologist, James Hutton (1726-
1797). Both these scientists advocated studying mechanisms that could potentially explain geological events that had occurred in the past - they were mechanistic rather than descriptive.

The first point is that during the voyage of the Beagle (1831-36), and for several years after that, Darwin considered himself primarily a geologist, ${ }^{25,26}$ rather than as a biologist, which was his later (and much better known) career. The evidence for this conclusion includes the following six points:

he wrote the three books on the geology of the voyage ("Geology of South America", "Coral Islands", "Geology of Volcanic Islands") but only edited the Zoology publications and was not involved with Botany publications (indeed his notes disappeared for over a century) ${ }^{27}$

his letters during the voyage of the Beagle show confidence on geological subjects, but show Darwin's concern about the inadequacy of his biological collecting $;^{28}$

some of his geological letters to colleagues had already been published before his return from the voyage, ${ }^{29}$

on his return from the voyage he joined the Geological Society of London (rather than the Linnean or Zoological Societies) and was an active participant in the Geological Society. He presented papers, published in its journal, was elected to its Council, and became its Foreign Secretary;

soon after the return of the Beagle he became a close associate with the leading geologist, Charles Lyell, and was a frequent visitor to his London home;

his early papers were almost exclusively on geology (Figure 2), often on subjects that were important geological topics at that time.

Figure 2 shows for a range of times his scientific publications in different subjects. The results are expressed as a percentage of total 
pages published on a subject (books are excluded from the count; the papers are collected together). ${ }^{29}$ Indeed, Darwin published little on biological topics until the 1850 s (though he was working on several biological subjects). However, the outline of his evolutionary theory, with its search for mechanisms that would lead to change, was developed in 1838 and he wrote extensive Abstracts in 1842 and 1844. Details on the young Charles Darwin as a geologist are available. ${ }^{26}$

However, by the middle of the 1840s Darwin had given up all field work in geology and was concentrating on biology. His studies of barnacles, fertilization of orchids, pigeons, climbing plants, the different forms of flowers in the same species, and earthworms are examples. But, as we have seen, he used his theory to select areas of research where he saw difficulties.

The young Darwin being a geologist is not nearly as restricting as such a statement might imply today in times of higher specialization within science. Lyell's "Principles of Geology" was in three volumes and the second was mainly on biological topics - biological factors that might help understand geological processes, such as the reduced rate of erosion from the presence of plant cover. That second volume started by considering the stability of species and, until recently, had probably the most detailed account in English of Lamarck's evolutionary theory (which Lyell certainly did not accept, though it is still a good summary of Lamarck). The rest of the volume discusses biogeography, mechanisms of dispersal of plants and animals, the potential for increase in population numbers, the regulation of population numbers, estimates of the rates at which species became extinct, etc. Lyell was well aware of competition for resources between plants, and quotes from de Candolle's book phrases such as "All plants ... are at war one with another" (see below). Until around the end of the $19^{\text {th }}$ century, geology included many aspects of environmental and historical biology as well as physical geography. For example, Lyell quotes frequently Prichard's "Researches into the Physical History of Man" ${ }^{30}$ However, from the present point of view, the important aspect was that some geologists sought mechanisms operating in the present that could explain events in the past; they did not see it as sufficient just to describe patterns in nature.

\section{Hutton: explaining the past from mechanisms now in operation}

So what are the implications of Darwin starting his professional career in geology? My conclusion is that Darwin's very mechanist approach to historical biology, as mentioned earlier, was ultimately derived from the Scottish geologist Charles Lyell (but who lived in London in his adult years), and it was accepted at the time that Lyell was strongly influenced by the approach of an earlier geologist, James Hutton, who was part of the 'Scottish Enlightenment' that flourished over the latter half of the $18^{\text {th }}$ century. In aiming to explain geological events in the remote past (that obviously could not have been observed by humans), both Hutton and Lyell sought mechanisms that could be studied in the present. The present is the key to the past, as geologists would now say. It was important for Hutton and Lyell to understand what constituted a scientific explanation of those ancient events. It is in this sense that Darwin extended Lyell and Hutton's mechanistic mode of reasoning (searching for current mechanisms that could explain the past) from geology into historical biology.

In the late $18^{\text {th }}$ century Hutton carefully defined his approach to geology; how he was going to reason about unobserved geological events and processes. He also wrote a series of volumes on philosophy, ${ }^{31}$ although that work does not seem to have been influential. However this emphasizes that Hutton was concerned about the 'scientific method'. I concentrate here on his major geological treatise, "Theory of the Earth", ${ }^{32}$ and the following quotations are taken from that book. The first is a brief description of his approach with its requirement for searching for operations that actually exist in the modern world and which might account for changes in the past. "But how shall we describe a process which nobody has seen performed, and of which no written history gives any account? ..., first, in examining the nature of those solid bodies, the history of which we want to know; and, 2dly, In examining the natural operations of the globe, in order to see if there now actually exist such operations, as, ... appear to have been necessary to their formation's2 (p.22, emphasis added). So we have to search for "natural operations of the globe"; the appropriate mechanisms. This second aspect, "if their now actually exist such operations" (mechanisms) is crucial to the reasoning of Hutton, and later Lyell and Darwin. An example of Hutton's reasoning is as follows; shells and coralline bodies are found in the hardest of rocks, but this is not the natural state of such bodies (shells and corals are normally much softer) - "Conse-quently, there must be a natural operation in the globe for consolidating and hardening its soft and loose materials' ${ }^{{ }^{2} 2}$ (p.33). From this prediction he studied the effects (in pottery kilns) of high temperatures and pressures on the hardening of materials such as clays. He discovered that high temperatures and pressures did turn 'clay' into 'rock'. Were such conditions found in Nature? "The only question, therefore, which it concerns us to decide at present, is, Whether those operations of extreme heat, and violent mechanic force, be only in the system as a matter of accident; or if, on the contrary, they are operations natural to the globe, and necessary in the production of such land as this which we inhabit? The answer to this is plain: These operations of the globe remain at present with undiminished activity, or in the fullness of their power."

Thus Hutton made predictions from his theory of the earth, and sought to test the predictions by experiments and observations. As another example, he predicted an important cycle of uplift, erosion, deposition of new strata, and uplift again. "I have long looked for the immediate junction of the secondary of low country strata with the alpine schistus, without finding it; the first place I observed it was at the north end of the island of Arran, at the mouth of Loch Ranza's2 (p.429), (both strata inclined at $45^{\circ}$ ). And again, "when one day, walking in the beautiful valley above the town of Jedburgh, I was surprised with the appearance of vertical strata in the bed of the river, where I was certain that the banks were composed of horizontal strata. I was soon satisfied with regard to this phenomenon, and rejoiced at my good fortune in stumbling upon an object so interesting to the natural history of the earth, and which I had been long looking for in

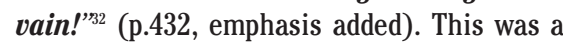
discovery of a geological 'unconformity', where the two strata were formed at very different geological periods - with a period of uplift and erosion between the lower and the upper strata - just as Hutton had predicted must occur.

He certainly recognized that his approach had hypotheses which he sought to test. For example, "at present, I hold this opinion only as a conjecture" (strata of marl often have thin calcareous strata with frequent cavities with different types of crystals - suggests these cavities may come from some hollow shells etc.) 32 (p.442). And again, "I have always conjectured that the waters of Giezer [Iceland] must be impregnated with flinty material by means of an alkaline substance, and so expressed my opinion ... ${ }^{\prime 32}$ (p.509); this was tested (and confirmed) when a traveller returned from Iceland with samples for him to test. Thus Hutton aimed at understanding the past in terms of processes that can be studied in the present, even though their knowledge of potential mechanisms was obviously very limited at the time. However, given current experience of the diversity of opinion, say on evolution by evolutionists, we expected there to be a range of views at any one time, and we turn briefly to that topic in order to help understand how over-simplification of views can mislead us.

\section{A range of views}

Although Lyell had a direct effect on the reasoning of the young Charles Darwin, the effect of Hutton was indirect, largely through Lyell. It 
is always important to recognise that at any time there will be a spectrum of views, and not to force all researchers into binary boxes such as being uniformitarian or catastrophist; or black versus white; or creationist versus evolutionist. Although Lyell acknowledged the earlier mechanistic approach of Hutton, he certainly acknowledges others such as the Italian geologist, Brocchi, whose untimely death in Egypt he much regretted. But there were other geologists who might accept a limited range of phenomena being explained by current mechanisms, but still allowed major unexplainable causes.

In the time of Hutton, most geologists, when considering complex events in the past, ${ }^{8}$ still appealed to massive but unknown forces that operated over relatively short time scales in the distant past. To this Hutton objected, "On the one hand, the Memoir now before us [Chevalier de Dolmieu] represents this great effect as belonging to an unknown cause, so far as we are ignorant of the grand debacle or catastrophe which changes the situation of the sea. On the other hand, the Theory now proposed, explains this operation, of forming those conical mountains of Sicily, and hollowing out its valleys, by known causes, and by employing powers the most necessary, the most constant, and the most general, that act upon the surface of the earth" (emphases added). It is this requirement of seeking for mechanisms in the present that can explain events in the past that was important eventually for the Darwinian approach to evolution.

As we will see later, it is important not to put researchers into discrete categories because, in practice, there will be a range of viewpoints and we are concentrating on those who attempted to explain past events by knowable causes. Cuvier is a particularly interesting case illustrating the diversity of views in that he made major advances in stratigraphy and comparative anatomy, but still did not accept that current mechanisms were anywhere near sufficient to explain past events. The following extracts are from a translation of Cuvier, ${ }^{33}$ and it should be noted that his title "Essay on the Theory of the Earth" was a direct response to Hutton's "Theory of the Earth". The first extract is especially relevant in that it claims the suddenness of changes, "most of the catastrophes which have occasioned them have been sudden; and this is easily proved, especially in regard to the last of them ... the carcasses of some large quadrupeds which the ice had arrested, and which are preserved even to the present day with their skin, their hair, and their flesh". This passage includes the footnote emphasizing (to Cuvier) the impossibility of slow and gradual revolutions; it is as follows.

"The two most remarkable phenomena of this kind, and which must banish for ever all idea of a slow and gradual revolution, are the rhinoceros discovered in 1771 ... and the elephant .... The last retained its flesh and skin ... was still in such high preservation, that it was eaten by dogs. ....former catastrophes, shew plainly enough that they were as sudden and violent like the last; ... Life, therefore, has been often disturbed on this earth by terrible events calamities which at their commencement, have perhaps moved and overturned to a great depth the entire outer crust of the globe, but which, since these first commotions, have uniformly acted at a less depth and less generally, (pp.15-6). This is especially interesting in that he accepts that some mechanisms can act 'uniformly', though it is unclear whether Cuvier is meaning only the constancy of the underlying physical forces (such as the gravitational constant), or whether he is implying constant rates of change (for example, of erosion). We see later that people such as Lyell accepted only the former (uniformity of the laws of nature), and rejected the latter (because the expected rates of change could vary).

It is clear that Cuvier fully understood, but rejected, any idea of current mechanisms being sufficient to explain past events. The following extract shows how he assumed it was sufficient for human history. “... as it has long been considered possible to explain the more ancient revolutions on its surface by means of these still existing causes; in the same manner as it is found easy to explain past events in political history, by an acquaintance with the passion and intrigues of the present day. But we shall presently see that unfortunately this is not the case in physical history; the thread of operation is here broken, the march of nature is changed, and none of the agents that she now employs were sufficient for the production of her ancient works." Certainly, the claim that "the thread of operation is here broken, the march of nature is changed" is a dramatic indication of an alternative view point - even though fully accepting that in human affairs we can explain historical events by understating current political intrigue. There will always be a range of views, and we need to avoid both extremes of forcing peoples' ideas into binary choices, whilst at the same time not becoming so relativistic that we lose sight of the key questions.

To continue with Hutton, the end of the $18^{\text {th }}$ century was a time when many scientists/ philosophers (including Lamarck) produced grand systems that sought to explain all natural phenomena. Hutton argued for more limited hypotheses that were judged by their consistency with the evidence. "We must admit, that, not having all the data which natural philosophy requires, we cannot pretend to explain every thing which appears; and that our theories, which necessarily are imperfect, are not to be considered erroneous when not explaining every thing which is in nature, but only when they are found contrary to or inconsistent with the laws of nature, which are known ..." And again $^{32}$ (p.298), "there may be many causes of which we are as yet ignorant". Thus we already see (in 1795) a strong emphasis on testing and hypotheses, combined with a search for mechanisms. It is important to note that no claim was made that we knew all the mechanisms. To the contrary, the last phrase, "there may be many causes of which we are as yet ignorant", is an important reminder that we must keep learning.

As he proposed it in the late $18^{\text {th }}$ century, Hutton's approach required a long time scale. As we will see, much later (1832) William Whewell, ${ }^{34}$ an opponent of the sufficiency of this mechanistic approach parodied it (probably unintentionally) under the name of 'Uniformatarianism'. Long before then Hutton had already complained that he was misinterpreted by another early author (Kirwan) who had suggested that Hutton assumed uniform rates of change. Rather, Hutton allowed rates of change to vary - the physical laws were constant. Thus rates of change could vary but the underlying mechanisms had to be those that could still be studied in the present. In the following passage Hutton complains about this misinterpretation. "In my theory, I advanced two propositions with regard to the economy of this world: First, That the solid matter of this earth, when exposed to the atmosphere, decay, and are resolved into loose materials, of which the vegetable soil upon the surface is in part composed; and, secondly, That these loose materials are washed away by currents of water, and thus carried into the sea." Kirwan had disagreed with this, and Hutton continued, "With regard to the proposition, our author [Kirwan] says, 'Soil is not constantly carried away by the water, even from mountains.' - I have not said that it is constantly washed away; for, while it is soil in which plants grow, it is not travelling to the sea, although it be on that road, and must there arrive in time. I have said, that it is necessarily washed away, that is, occasionally $^{\prime 32}$ (pp.205-6, emphasis added). Later both Lyell and Darwin had similar complaints that others assumed they implied equal rates of change. ${ }^{35,36}$

My conclusion from these quotations is that Hutton expressed a methodology that we would certainly regard as scientific in the modern sense. He was very conscious of the need to clarify the basis of reasoning about the mechanisms that could explain ancient events, and he made predictions and tested them. However, Hutton did not seem to convince the majority of geologists of his period and his search for mechanisms as necessary and sufficient did not become more generally accepted until after the work of Lyell was published in the 1830 s. Hutton was further along the spectrum towards the modern understanding than most geologists of his time. 


\section{Lyell's "Principles of Geology"}

Charles Lyell had a direct impact on the thinking of Darwin, and coming after Hutton had the advantage of another 35 years of scientific knowledge. Lyell was eventually able to persuade most geologists of the sufficiency (for geology) of geological mechanisms that could be studied in the present (the equivalent of Figure 1C for geology). Lyell's $\mathrm{s}^{24}$ subtitle in the first edition of his "Principles of Geology" ("an attempt to explain the former changes of the earth's surface, by reference to causes now in operation") puts his mechanistic approach right into the front page of his work - the emphasis is on studying causes/mechanisms not just describing the patterns in nature.

As mentioned earlier, there is a very human tendency to over-simplify complex matters into 2-way (binary) choices. For example, the binary uniformitarian/catastrophist distinction ${ }^{34}$ of Whewell is incorrect and far too simplistic (Appendix 1). Whewell, who at the same time advocated what we would now call a hypothetico-deductive approach, in his review of the second volume of Lyell's Principles ${ }^{24}$, suggested, "These two opinions will probably for some time divide the geological world into two sects, which may perhaps be designated as the 'Uniformitarians' and the 'Catastrophists'. The latter has undoubtedly been of late the prevalent doctrine, ... Indeed, we think it ought to be so. ${ }^{3{ }^{34}}$ (p.126). This overly-simplistic binary choice seems to have dominated thought for 175 years! But it misses some of the most interesting aspects, such as the search for mechanisms that could explain past changes. And it misses the fact that Lyell's Principles ${ }^{24}$ proposed several catastrophes, including a break-out of the Great Lakes. For example, "the time will come, however distant, when a deluge will lay waste a considerable part of the American continent. No hypothetical agency is required to cause the sudden escape of the confined waters". ${ }^{24}$ Lyell goes on to argue that such events would be rare, and 'catastrophes' should not be the default explanation. Other examples of regional catastrophes are mentioned, including the raising of land around Gibraltar leading to the straights being blocked, with consequential drying up of the Mediterranean (with major changes in the biota of the region). The reverse is then suggested as a possibility, the lowering of the straights until there is a major influx of seawater back in again. There is even reference to the possibility of comet impacts! The main point was that Lyell wanted even catastrophes to have 'known causes', and was against invoking catastrophes as a short-sighted knee-jerk response of not having sufficient knowledge to being able to propose (or search for) known mechanisms.

It is not the place here to present detailed extracts from Lyell on his geological work; and although most of the three volumes are on geology he gives extensive statements on ecology/ biology. Indeed these are important precursors to much of Darwin's reasoning in transferring the mechanistic approach of Lyell from geology into biology - even though at the time Lyell rejected evolution. Lyell's understanding of ecology and biology was strongly influenced by the Swiss botanist Augustin de Candolle. During Lyell's geological field trip to Italy, after meeting one of de Candolle's students there, he made a trip over the Alps into Switzerland in the middle of winter in order to visit de Candolle.

The influence of de Candolle can be seen in the following extracts from Lyell ${ }^{24}$ about biolo$\mathrm{gy}$, "the most fertile variety would always, in the end, prevail over the more sterile" (Vol. II, p.34), "Unhealthy plants are the first which are cut off by causes prejudicial to the species, being usually stifled by more vigorous individuals of their own kind.... In the universal struggle for existence, the right of the strongest eventually prevails" (Vol.II, pp.55-6). "All plants of a given country ... are at war, one with another. The first which establish themselves by chance in a particular spot, tend ... to exclude other species, the greater choke the smaller, the longest livers ... the more prolific.... In this continual strife, it is not always the resources of the plant itself ... Its success depends, in a great measure, on the number of its foes and allies among the animals and plants inhabiting the

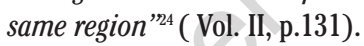

These extracts from Lyell, including intraand inter-specific competition and the universal struggle for existence, are taken out of context and could appear a bit ruthless. In context they are less so and Lyell assumes a 'Balance of Nature'. It is important that from such writings, Darwin was certainly familiar with ideas such as competition within nature long before he read Malthus. Many modern authors assume that Darwin only became aware of ideas about competition later. Although Malthus may have given the ideas a stronger mathematical basis, earlier authors were well aware of competition in nature and the limitation of resources. Returning to Lyell, he assumed that species (once created) were 'left to their own devices', and flourished or waned strictly according to the ecological mechanisms (principles) that could be studied in the present. This ecological/populational aspect of Lyell's "Principles of Geology" is an important intermediate step in the introduction of highly mechanistic reasoning into historical biology. In Lyell's view, each species was created separately, but then it was left to the laws of nature whether a given species flourished or declined (even to the extent of going extinct). A student of Lyell would have found several precursors of Darwin's mechanism for biological evolution within Lyell's "Principles of Geology". Both the general approach of searching for mechanisms to explain the past, plus many details of biological mechanisms, were present in Lyell.

Darwin certainly went well beyond Lyell's reasoning. Two important examples are Darwin's move away from a deterministic science to include stochastic effects, and his elimination of purpose (or ultimate causes) from science. ${ }^{37}$ That the latter was still part of Lyell's thinking is shown in the following. "It seems also reasonable to conclude, that the power bestowed on the horse, the dog, the ox, the sheep, the cat, and the many species of domestic fowls, of supporting almost every climate, was given expressly to enable them to follow man throughout all parts of the globe - in order that we might obtain their services, and they our protection ${ }^{\prime 24}$ (Vol II, p.44).

The conclusions I draw from this section are as follows:

it was significant that the young Darwin was a geologist - geology was a broader discipline than now envisaged and included biological effects on the physical environment;

both Hutton and Lyell were well aware of the need for conjecture, hypothesis and testing, as well as measurement and experimentation in science;

again, both Hutton and Lyell sought to explain past events in geology by mechanisms that could be studied in the present (including biological effects on such events as rates of erosion);

Darwin's insistence on a mechanism of evolution based on known causes is an application to historical biology of Hutton and Lyell's methods (including the necessity of a long time scale);

Lyell (from de Candolle) already recognized competition in nature, and Darwin was already prepared for it when he read Malthus several years later.

Darwin's attitude of searching for mechanisms was thus largely set during the voyage of the Beagle when he convinced himself of the superiority of Lyell's (and thus Hutton's) approach of searching for mechanisms from the present that could help explain the past. Darwin certainly left geology behind to become a full-time biologist, but his intellectual legacy is important to his approach to the science of explaining events in the past by mechanisms that can be studied in the present.

\section{Discussion}

A conclusion from this study is that Charles Darwin worked in a way that is surprisingly consistent with the ideas of Karl Popper on how the best scientists work. This conclusion was not expected at the start of the study when 
Darwin was considered, at least by evolutionists, a poor theorizer who simply collected a lot of data and just happened to be in the right place at the right time, and Popper was considered somewhat hostile to evolutionary theory as unfalsifiable, ${ }^{38}$ although Popper certainly later accepted evolution. ${ }^{39}$ Rather, we see Darwin as well aware of the philosophy of knowledge of the time, an excellent theorizer, well aware of the necessity of hypotheses, and perhaps even ahead of most scientists and philosophers of knowledge of his time in trying to falsify hypotheses. Finally, there is the aspect, borrowed from geology, of searching for the mechanisms that could explain past changes.

Does the analysis here answer our initial question on why in several aspects Darwin was well ahead of his biological contemporaries? At best it is an incomplete answer, but I venture that it is an important part of any answer. His theoretical/mechanistic approach from his geological background was not shared generally by biologists seeking to understand the origins of biodiversity. Certainly, there were physiologists with similar attitudes of studying mechanisms, but they were more involved with physiology of existing species, rather than with the origins of biodiversity. Even today, we find significant resistance to Darwin's claim (Figure 1C) that the processes of microevolution are sufficient for all of macroevolution. ${ }^{40}$

Is it important in practice that we focus on hypotheses where mechanisms are available that would lead to the predicted outcomes? I will argue, politely if necessary, that we modern evolutionists have sometimes forgotten Darwin's very mechanistic reasoning, and have put forward ideas that are not supported by the known mechanisms. Appendix 2 gives five cases where I think evolutionary claims are made that are not backed up by the mechanisms available - or ignore some other aspect of the data. These five examples, though they may illustrate limitations of more recent evolutionary science, should not distract us from what can be achieved in good evolutionary thought. The main message is that Charles Darwin was both a strongly hypothetico-deductive researcher, and sought for mechanisms working in the present that could explain changes in the past.

The subject of Darwin being a good theorizer is well known to the specialists, ${ }^{41,42}$ (and other references cited throughout the text). However, there are two aspects that warrant further comment. One is that for some reason, this conclusion has not made a real impact on biologists, and it would certainly help if both the hypothetico-deductive reasoning and mechanistic approaches were better appreciated by evolutionists. But the other side of the coin is that there are aspects where the input of biologists is needed to help identify key questions - such as the necessity of understanding mechanisms leading to change. Biologists can contribute here to the understanding of how science really progresses.

It is important that in our teaching of science we give our students a feeling for the excitement of science, the hypotheses, counter-hypotheses, tests and failed tests, imagination, caution and critical analysis. We must avoid being trapped by overly-restricted binary choices, such as uniformitarianism versus catastrophism (Appendix 1), creation versus evolution, or Intelligent Design versus evolution, punctuated equilibria versus phyletic gradualism (Appendix 2), etc. The erroneous uniformitarian-catastrophism division has misled researchers for nearly 200 years; the problem of over-simplified binary choices is still present today. We have seen that excellent science proposing and testing hypothesis has been practiced over many centuries, and that the search for mechanisms that can explain the past has been a focus over that time. Describing patterns in nature is useful, but we are limited if we do not even attempt to understand the underlying mechanisms leading to those patterns. Perhaps, for example, the teaching of evolution today focuses too much on the description of patterns and relationships, and still needs to get more towards the underlying mechanisms. Integrating microand macro-evolution is still a key issue.

In an evolutionary theory of knowledge we must emphasize the importance of our current knowledge as our building blocks but must also discuss the unsolved questions. I hope that examples of great scientists testing and rejecting their own hypotheses, and searching for mechanisms will help the education of the next generation of scientists. Will they be able to answer Darwin's claim, and demonstrate the sufficiency of microevolutionary processes for macroevolution? If we can, then it is time that evolutionists were more proactive in promoting evolution, both as central to all of biology, and in demonstrating to the general public that evolution is brilliant science. We should not be on the defensive, defending ourselves only when creationists or Intelligent Designers attack the education system. Evolutionists need to take the initiative by emphasizing the outstanding evolutionary science available.

\section{Appendix 1. Uniformitarianism and catastrophism; avoiding simplistic binary choices}

Though still simplistic, it is helpful to consider the questions proposed by Lyell in at least five categories. The first three, indicated by ' $\checkmark$ ', Lyell would accept, the last two he rejects.

$\checkmark 1$. The laws of nature are "uniform. In his frontispiece to his Principles ${ }^{24}$ Lyell uses an extract from Playfair (a biographer and interpreter of Hutton) "the economy of Nature has been uniform, and her laws are the only things that have resisted the general movement. The rivers and the rocks, the seas and the continents have been changed in all their parts; but the laws which direct those changes, and the rules to which they are subject, have remained invariably the same".

$\checkmark 2$. These fundamental physical laws lead to variable rates of change of geological processes, including uplift, erosion, volcanic activity, climate change, etc.

$\checkmark 3$. Regional and larger catastrophes are part of the system, but they operate by known (or knowable) mechanisms - even including comet impacts.

$x$ 4. There is no 'progression' of any kind of plant and animal forms through time. In the early 1830s Lyell rejected any form of 'evolution' - whether natural or guided.

$x$ 5. Large catastrophes by unknown (or unknowable) mechanisms are necessary to account for past changes.

Whewell's division into Uniformitarianism and Catastrophism is therefore highly oversimplified - basically it concentrates on options 1 (uniformity of physical laws) and 5 (catastrophes by unknown causes). Concentrating on 1 and 2 might be appropriate for ideas of evolution via orthogenesis or by phyletic gradualism, but certainly the constant rates did not represent either Hutton's or Lyell's views - nor later Darwin's. The primary point here is that we must always be careful of oversimplified binary choices. It is very easy to get trapped into considering a complex range of options as just a simple binary choice.

\section{Appendix 2. Five modern examples lacking mechanistic reasoning}

There are areas where I think we evolutionary biologists have fallen below the standards initially used by Darwin. The following five examples appear to be where we have apparently not concentrated on testable mechanisms for our hypotheses. The examples include: 
- punctuated equilibria;

- the nature of species;

- focusing on the 'Tree of Life' (rather than Darwin's 'theory of descent with modification');

vicariance models for biogeographic distributions; and

the multiregional model for the origin of modern humans.

The first, punctuated equilibrium, has been covered previously. ${ }^{35,36}$ The problem was that the proponents of the punctuated equilibrium theory assumed that Darwin's mechanism was 'phyletic gradualism' (which would include orthogenesis). However, under any Darwinian mechanism the suggestion of "phyletic gradualism' is unlikely because there are no known mechanisms that would lead to slow and continuous rates of morphological change and/or speciation (though perhaps a strict molecular clock would be an example for macromolecules). The punctuated equilibria/phyletic gradualism debate is an example of Whewell's unfortunate binary division ${ }^{34}$ (Catastrophism vs. Uniformitarianism, see Appendix 1). Darwin (and earlier Lyell and Hutton) protested that they were not assuming long-term even rates (see above for Hutton and Lyell; and for $\left.\operatorname{Darwin}^{35,36}\right)$.

A second example, the nature of species, has emerged recently as an important question. ${ }^{43,44}$ Darwin assumed a basic continuum from individuals, populations, varieties, sibling species, species, species complexes, and genera, and saw no mechanism that would universally differentiate the species level on the continuum ${ }^{43}$ Recent work (especially with molecular data) is reinforcing that conclusion. ${ }^{44}$ Sometimes there are clear isolating mechanisms, sometimes there are not, etc. Hybridization and introgression, widely accepted in plants, is increasingly being found with animals. There seems nothing at the species level that is universal across eukaryotes, let alone in archaea and bacteria. The biological species concept is almost certainly the best we have, but cannot be expected to work universally. There is no guarantee that two species that are well differentiated at the present may not merge again later when climate change (for example) alters their distribution. An individual plant, for example, does not 'know' what species it is supposed to belong to. Certainly, species may usually be real, but there is no guarantee of 'always'.

A third example is also interesting because of the debate about the so-called 'Tree of Life' versus the high extent of lateral transfer in prokaryotes - leading to a network. The 'Tree of Life' is a biblical concept, dating back to the book of Genesis, and Darwin was always careful to describe his proposal as "my theory of descent with modification" (D. Penny, in preparation). Descent with modification clear- ly encompasses lateral gene transfer (although that was certainly not known in the $19^{\text {th }}$ century) but also hybridization, introgression and lineage sorting. The reasons why Darwin strongly preferred the 'descent with modification', while calling the 'Tree of life' a 'useful simile', are not clear. Perhaps the best explanation focuses on his insistence on looking for mechanisms, and not being very interested in just describing 'patterns in the data'.

The fourth example is the use of vicariance models for biogeographic distributions in the 1970 s, where it was just asserted that plants and animals moved passively with continental drift. The known mechanisms of plant and animal dispersal were simply ignored in favor of passive dispersal. Fortunately, molecular data ${ }^{45}$ eventually overrode the assertions of vicariance biogeographers, but the point here is that the vicariance assertion, when it was made, simply ignored the large amount of information about mechanisms of dispersal.

The final example here, the multiregional model for modern human origins has been quite popular, to the extent of being presented in text books as an alternative to the 'Out of Africa' model. However, the multiregional model was essentially disproved by the results of Ferris et al., ${ }^{46}$ well before the multiregional theory was even formalized! These authors showed that modern humans had relatively low genetic diversity - compared with other mammal species including chimpanzees and gorillas. From the viewpoint of genetic mechanisms, the problem was in explaining why humans had low genetic diversity. In contrast, any multiregional model (with a long-term population of modern humans in Africa, Europe and Asia) would result in high genetic diversity. Again, such issues were ignored by advocates of 'multiregionalism', showing again the scientific perils of ignoring 'known mechanisms'.

\section{References}

1. Mayr E, Provine WB, editors. The Evolutionary Synthesis: Perspectives on the unification of biology. Cambridge MA: Harvard Univ Press; 1980.

2. Bowler FJ. The eclipse of Darwinism: antiDarwinian evolution theories in the decades around 1900. Baltimore: Johns Hopkins University Press; 1983.

3. Scott DH. The present position of the theory of descent, in relation to the early history of plants. Nature 1921;108:153-9.

4. Watson DMS. Presidential Address to Zoology section, British Assoc Advanc Science, 1929. In: The genetical theory of natural selection: a complete variorum edition. RA Fisher, JH. Bennett. Oxford:
Oxford University Press; 1999.

5. Penny D, Hendy MD, Steel MA. Testing the theory of descent. pp 155-83 in: Miyamoto M, Cracraft J. editors. Phylogenetic Analysis of DNA Sequences. Oxford, Oxford University Press; 1991.

6. Penny D. 20 points on the structure and testability of Darwin's theory. Evol Educ Outreach 2009 (in press).

7. Riddiford A, Penny D. The scientific status of modern evolutionary theory. pp1-38 in: Evolutionary theory: paths into the future. (Pollard JW, editor), London: John Wiley; 1984.

8. Cannon WF. Charles Lyell, radical actualism, and theory. Brit J Hist Sci 1976; 9:10420.

9. Mayr E. Darwin's five theories of evolution. pp 755-772 in: The Darwinian Heritage. (Kohn D, editor), Princeton: Princeton University Press; 1985.

10. Ghiselin MT. The triumph of the Darwinian method. Berkeley CA: University of California Press; 1969.

11. Ayala FJ. Darwin and the scientific method. Proc Natl Acad Sci USA 2009; 106: 10033-9.

12. Darwin C. The Autobiography of Charles Darwin. (Barlow N, editor), New York: Norton; 1969.

13. Schweber SS. The origin of The Origin revisited. J Hist Biol 1977;10:219-316.

14. Ruse M. Darwin's debt to philosophy: an examination of the influence of the philosophical ideas of John H.W. Herschel and William Whewell on the development of Charles Darwin's theory of evolution. Stud. Hist Philos Sci 1975; 6:159-81.

15. Whewell W. The philosophy of the inductive sciences London: JW Parker; 1840.

16. Burkhardt F, Smith S, editors. The Correspondence of Charles Darwin, Volume 2 1837-1843. Cambridge: Cambridge University Press; 1986.

17. Popper KR. The logic of scientific discovery. London: Hutchinson; 1972.

18. Burkhardt F, Smith S, editors. The Correspondence of Charles Darwin, Volume 6 1856-1857 Cambridge: Cambridge University Press; 1990.

19. Burkhardt F, Porter DM, Harvey J. and Richmond M, editors. The Correspondence of Charles Darwin, Volume 91861. Cambridge: Cambridge University Press; 1994.

20. Darwin C. On the Origin of Species London: Murray; 1859.

21. Allan M. Darwin and his flowers: the key to natural selection. London: Faber and Faber; 1977.

22. Jones D. Human nature: the remix. Nature 2009;457:780-3.

23. Rudwick MJS. Worlds before Adam: the reconstruction of geohistory in the age of 
reform. Chicago: University of Chicago Press; 2008.

24. Lyell C. Principles of Geology, being an attempt to explain the former changes of the earth's surface, by reference to causes now in operation, 3 Vols; 1830-33. (Reprinted, with introduction by Rudwick MJS.: Lehre: Verlag von J Cramer; 1970).

25. Rudwick MJS. Charles Darwin in London: The integration of public and private science. Isis 1982;73:186-206.

26. Herbert S. Charles Darwin, geologist. Ithaca: Cornell University Press; 2005.

27. Porter DM. Charles Darwin's vascular plant specimens from the voyage of HMS Beagle. Bot J Linn Soci 1986;93:1-172.

28. Sulloway FJ. Darwin's early intellectual development: an overview of the Beagle voyage 1831-6. pp121-54 in: The Darwinian Heritage. (Kohn D, editor). Princeton: Princeton University Press; 1985.

29. Barrett PH, editor. The collected papers of Charles Darwin. Chicago: Chicago University Press; 1977.

30. Prichard JC. Researches into the Physical History of Man. London: John and Arthur Arch; 1813 (reprint, edited Stocking GW Jr. Chicago: Chicago University Press; 1973).
31. Jones P. An outline of the philosophy of James Hutton. In: Philosophers of the Scottish Enlightenment (Hope V, ed.), pp 182-210. Edinburgh: Edinburgh University Press; 1984.

32. Hutton J. Theory of the Earth, with proofs and illustrations. 2 volumes, 1795. Reprinted (1959 Weinheim/Bergstr: H.R. Engelmann (J. Cramer) and Codicote, Herts: Wheldon and Wesley):

33. Cuvier G. Essay on the Theory of the Earth: with Mineralogical Notes by Jameson. Edinburgh; 1817 (Reprinted, New York: Arno Press; 1978).

34. Whewell W. Lyell's Geology, Vol. 2. Quart Rev. 1832; 47: 103-32.

35. Penny D. Charles Darwin, gradualism and punctuated equilibrium. Syst Zool 1983; 31:72-4.

36. Rhodes FHT. Gradualism, punctuated equilibrium and the origin of species. Nature 1983;305:269-72.

37. Dennett D. Darwin's "strange inversion of reasoning”. Proc Natl Acad. Sci USA 2009; 106:10061-5.

38. Penny D, Foulds LR, Hendy MD. Testing the theory of evolution by comparing phylogenetic trees constructed from five different protein sequences. Nature 1982;
297:197-200.

39. Popper KR. Towards an evolutionary theory of knowledge. pp 27-51, in: A world of propensities. Bristol: Thoemmes; 1990.

40. Penny D, Phillips MJ. The rise of birds and mammals: Are microevolutionary processes sufficient for macroevolution. Trends Ecol Evol 2004;19:516-22.

41. Bowler PJ. Darwin's originality. Science. 2009;323:223-6.

42. Ruse M. The Darwinian revolution: rethinking its meaning and significance. Proc Natl Acad Sci USA 2009;106:10040-7.

43. Mallet J. Mayr's view of Darwin: was Darwin wrong about speciation? Biol J Linn Soc 2008;95:3-16.

44. Mallet J. Hybridization, ecological races and the nature of species: empirical evidence for the ease of speciation. Philos Trans R Soc B 2008;363:2971-86.

45. Hurr KA, Lockhart PJ, Heenan PB, Penny D. Evidence for the recent dispersal of Sophora (Leguminosae) around the Southern Oceans: Molecular data. J Biogeog 1999;26:565-77.

46. Ferris SD, Brown WM, Davidson WS, Wilson AC. Extensive polymorphism in the mitochondrial DNA of apes. Proc Natl Acad Sci USA 1981;78:6319-23. 